\title{
Pengaruh Konten Instagram Ads @Luxebarbershop Terhadap Peningkatan Brand Awareness
}

\author{
Hendi Paramitha ${ }^{1}$ dan Yohannes Don Bosco Doho ${ }^{2}$ \\ Institut Komunikasi dan Bisnis LSPR, Jakarta, Indonesia
}

\begin{abstract}
ABSTRAK
Di era yang serba digital ini, berbagai media sosial memberikan kemudahan dan inovasi untuk bersaing di dunia bisnis demi tujuan positif yang akan dicapai serta sebagai cara baru dalam mendapatkan awareness. Salah satunya adalah Instagram ads, yang memberikan keunggulan untuk mendapatkan lebih banyak brand awareness. Salah satu bisnis barbershop yang menggunakan Instagram ads adalah Luxebarbershop. Penelitian ini bertujuan untuk mengetahui adakah pengaruh dan seberapa besar pengaruh Instagram ads terhadap peningkatan brand awareness Luxebarbershop, Sarinah, Jakarta. Dalam penelitian ini digunakan model kemungkinan elaborasi (Elaboration Likelihood Theory) dengan dua dimensi pengukuran variabel X (Instagram ads) yaitu context, communication, collaboration, connection. Terdapat juga empat dimensi pengukur variabel Y (brand awareness) yaitu unware of a brand, brand recognition, brand recall, top of mind. Penelitian ini menggunakan metode penelitian kuantitatif dengan sampel penelitian diambil melalui kuesioner online kepada 86 orang responden yang belum pernah mengunjungi Luxebarbershop dengan teknik non-probability sampling - purposive sampling. Penilitian ini menghasilkan pernyataan adanya pengaruh antara Instagram ads terhadap peningkatan brand awareness Luxebarbershop, Sarinah, Jakarta. Hasil analisis data juga menunjukkan bahwa Instagram ads memiliki hubungan sangat kuat dan positif dengan nilai koefisien korelasi sebesar 0,914 dan nilai kontribusi sebesar 83,35\% terhadap peningkatan brand awareness Luxebarbershop, Sarinah, Jakarta.
\end{abstract}

Kata kunci: barbershop; brand awareness; instagram ads; media sosial

\begin{abstract}
In this all-digital era, various social media provide convenience and innovation to compete in the business world for positive goals to be achieved and as a new way of gaining awareness. One of them is Instagram ads, which give you the advantage of getting more brand awareness. One of the barbershop businesses that use Instagram ads is Luxebarbershop. This study aims to determine whether there is an influence and how much influence does Instagram ads have on increasing brand awareness of Luxebarbershop, Sarinah, Jakarta. The theory used in this study is the elaboration probability model (Elaboration Likelihood Theory) and there are two dimensions to measure the $X$ variable (Instagram ads), namely context, communication, collaboration, connection. Besides, there are four dimensions to measure the Yvariable (brand awareness), namely unaware of a brand, brand recognition, brand recall, top of mind. This research uses quantitative research methods. The sample was taken in this study through an online questionnaire to 86 respondents who had never visited Luxebarbershop with an accidental sampling technique. The results of this study indicate that there is an influence between Instagram ads on increasing brand awareness of Luxebarbershop, Sarinah, Jakarta. The results of data analysis also show that Instagram ads have a very strong and positive relationship.
\end{abstract}

Keywords: barbershop; brand awareness; instagram ads; social media 


\section{PENDAHULUAN}

Kita hidup di dalam dunia yang nyaris tanpa batas. Media sosial menjadi salah satu sarana yang menjembatani sekat yang ada. Beragam Informasi berseliweran di media sosial bersifat real time dan memiliki pengaruh yang signifikan bagi seluruh kehidupan manusia termasuk pola berbelanja bagi masyarakat. Oleh sebab itulah media sosial dinilai lebih efisien, murah, dan tepat sasaran. Peran internet pada masa kini tidak hanya sekedar sebagai sarana mencari informasi, tapi juga mempunyai potensi besar sebagai media pemasaran hingga penyebaran ideologi tertentu.

Di era yang serba digital saat ini, inovasi demi inovasi akan bersaing di dunia bisnis demi tujuan positif yang akan dicapai. Memberikan banyak kemudahan, serta sebagai cara baru dalam mendapatkan awareness, dan juga menciptakan komunikasi dua arah serta interaksi yang mendukung antara sesama pengguna, interaksi ini kemudian membuat kata lain yang di sebut sebagai media sosial.

Kini media sosial telah menjadi alat yang paling sering digunakan setiap individu dan kelompok untuk membuat konten apa saja lalu membagikannya kepada orang atau komunitas lain (Paquette, 2013). Demikian pula apa yang ditegaskan oleh Paquette(2013) di mana media sosial tidak hanya berfungsi sebagai pertukaran informasi dengan keluarga maupun teman, melainkan telah berkembang menjadi media yang di mana para pelanggan dapat mengenali serta mempelajari lebih lanjut tentang perusahaan yang mereka sukai (Shanker, 2011). Dengan penjelasan ini maka dapat disimpulkan bahwa media sosial merupakan suatu platform terjadinya proses pertukaran informasi dengan individu dan kelompok lainnya, serta media sosial juga dapat dimanfaatkan oleh para pelanggan untuk lebih memahami perusahaan-perusahaan yang mereka inginkan.

Hal tersebut banyak dimanfaatkan oleh perusahaan untuk menggunakan internet dan media sosial sebagai alat komunikasi pemasarannya. Kehadiran media baru membawa banyak kegunaan bagi para produsen atau pemberi jasa. Pelanggan atau konsumen pun dengan mudah memilih produk atau jasa yang dikehendaki dengan memanfaatkan fitur-fitur atau aplikasi online. Salah satu media sosial yang marak dimanfaatkan oleh pemasar adalah Instagram. Media sosial yang dimanfaatkan oleh industri jasa yang menjadi fokus penelitian ini adalah salah satu fitur dari Instagram yaitu Instagram Ads. Instagram Ads itu sendiri tidak lain dari sebuah platform iklan di media sosial. Instagram Ads merupakan sebuah bentuk layanan yang memungkinkan para penggunanya untuk membuat iklan di feed Instagram dan Instagram Stories. Manfaat itulah yang dimaksimalkan oleh Luxebarbershop. Adapun pertimbangan dari pemberi jasa karena kemudahan menjalin engagement antara Luxebarbershop dengan pelanggan atau konsumen. Pertimbangan lainnya adalah karena Instagram digunakan oleh banyak orang.

Sagiyanto \& Sulfiah (2020), mendeskripsikan Instagram sebagai sebuah aplikasi yang dapat dimanfaatkan untuk untuk membagi konten visual, baik berupa foto maupun video. Instagram juga dikenal sebagai salah satu media sosial yang sangat bermanfaat sebagai saluran pemasaran langsung dalam bentuk berbagi pesan. Melalui Instagram, para konsumen dapat melihat produk maupun jasa yang ditawarkan dan dikemas melalui konten foto maupun video singkat. 
Kualitas Instagram yang ditampilkan dalam gambar atau foto yang dikemas menarik agar membentuk hubungan emosional dengan pelanggan (Zimmerman, dalam Nummila, 2015). Begitu pula dengan kredibilitas endorser yang terlibat sebagai komunikator dalam proses pemasaran suatu produk. Banyak penelitian yang mendukung generalisasi kredibilitas mempengaruhi sikap dan perilaku niat membeli (Lafferty et al., 2002).

We are Social, menyatakan bahwa platform media sosial yang sering digunakan di Indonesia per Januari 2019 adalah Youtube (88\%), WhatsApp (83\%) dan oleh Facebook (81\%). Posisi selanjutnya ditempati oleh Instagram (80\%), Line (59\%), Twitter (52\%), dan Facebook Messenger (47\%). Sisanya ditempati secara berurutan oleh Blackberry Messenger, LinkedIn, Pinterest, Skype, WeChat, Snapchat, Path, Tumblr dan Reddit.

Berdasarkan data di atas, bahwa ada 80\% pengguna media sosial Instagram, maka Instagram merupakan salah satu media yang potensial untuk digunakan sebagai media promosi untuk meningkatkan brand awareness dari Luxebarbershop, Sarinah, Jakarta.

Pada saat ekonomi dunia dan juga Indonesia sedang mengalami resesi, bisnis jasa seperti barbershop justru hampir tidak terkena dampaknya sama sekali, Luxebarbershop, Sarinah, Jakarta sebagai contohnya, Meningkatnya kesadaran kaum pria untuk berpenampilan menarik di setiap kesempatan, memberikan dampak positif pada perkembangan barbershop di Indonesia.

Kompetitor yang berada di sekitar Sarinah adalah barbershop CityCut dan barbershop Bawah Pohon, walaupun mempunyai tarif harga gunting yang lebih murah Rp 5000 (lima ribu rupiah) yaitu $\mathrm{Rp} 70.000$ (tujuh puluh ribu rupiah) tetapi Luxebarbershop mempunyai keunggulan yang diberikan daripada kompetitornya, yaitu adanya layanan yang diberikan setelah gunting rambut, contohnya: cuci rambut, balsam muka, handuk hangat, pijat punggung, hair tonic, dan penggunaan pomade untuk styling rambutnya.

Tujuan dari Luxebarbershop berpromosi melalui media sosial Instagram adalah untuk menguatkan brand, menjaga konsistensi brand, menjaga image dan menjadikan Luxebarbershop selain banyak yang mengenal dan mampu bersaing dengan kompetitor lainnya, Luxebarbershop juga bertujuan menjadi top of mind bagi konsumen yang ingin gunting rambut dengan tempat dan layanan yang nyaman, ramah dan hasil yang memuaskan di lokasi pusat kota yaitu Sarinah, Jakarta. Untuk itu pertanyaan penelitiannya adalah apakah terdapat pengaruh dan seberapa besar pengaruh Instagram ads Luxebarbershop terhadap brand awareness.

\section{Kerangka Teoritis}

Secara ontologis dan aksiologis, konsep dan teori yang digunakan di sini dapat dikategorikan ke dalam komunikasi pemasaran. Bila merujuk kepada pandangan Patrick et al (2017, p. 3), maka komunikasi pemasaran tidak lain merupakan sebuah proses di mana perusahaan melakukan kegiatan pemasaran untuk menginformasikan merek, produk atau jasa kepada para pelanggannya. Lalu berdasarkan informasi-informasi tersebut, para pelanggan dapat memberikan suatu tanggapan atau persepsi hingga keputusan memilih merek ataupun produk/jasa yang ditawarkan, sehingga dapat tercipta hubungan antaran yang harmonis dan kuat antara perusahaan dengan pelanggan. 


\section{Elaboration Likelihood Model}

Teori utama dalam penelitian ini adalah Elaboration Likelihood Theory. Menurut Perloff (2010), elaboration (elaborasi) mengarah pada sejauh mana seseorang berpikir tentang mental argumen yang terdapat di dalam sebuah komunikasi. Sedangkan likelihood (probabilitas), mengarah pada kemungkinan bahwa suatu peristiwa yang akan terjadi dapat di jadikan suatu acuan fakta bahwa elaborasi mungkin dapat terjadi atau tidak terjadi.

Teori Elaboration Likelihood Model digunakan untuk mengukur bagaimana target audience mengolah pesan yang disampaikan oleh Instagram ads Luxebarbershop, Sarinah, Jakarta, karena isi konten merupakan salah satu indikator penting dalam mengetahui pengaruh terhadap brand awareness Luxebarbershop, Sarinah, Jakarta.

\section{Komunikasi Persuasif}

Teori-teori pendukung lainnya di antaranya adalah Teori Komunikasi Persuasif, Menurut Prigusnanto (2014), kualitas produk atau jasa tidak akan sampai dan dikenal oleh konsumen tanpa adanya kekuatan persuasif di dalam komunikasi. Teori Pemasaran, menurut Prisgunanto (2014) "Pemasaran merupakan segala sarana yang digunakan untuk mempengaruhi konsumen agar terpengaruh dan percaya dengan produk yang ditawarkan”. Dan Instagram ads termasuk dalam dimensi promosi yang ditampilkan secara visual. Teori Digital Marketing yaitu aktivitas komunikasi pemasaran yang menggunakan media elektronik/online dalam menarik konsumen atau perusahaan dalam berbagai bentuk produk atau jasa, (Kotler \& Keller, 2016).

\section{Media Sosial}

Teori Media Sosial Marketing menurut Rouse (2011), media sosial marketing adalah bentuk dari internet marketing yang memanfaatkan situs jejaring sosial sebagai alat pemasaran. Teori promosi merupakan kombinasi dari penjualan perorangan, periklanan, promosi penjualan, dan hubungan masyarakat yang membantu pencapaian tujuan perusahaan (Stanton, 2003). Media sosial telah dipahami sebagai salah satu platform yang dapat memberikan peluang baru bagi perusahaan dalam meningkatkan daya saing perusahaan, yaitu dengan cara-cara baru seperti mempergunakan media sosial sebagai alat interaktif (Tarsakoo \& Charoensukmongkol, 2020; Chikandiwa et al, 2013). Sementara itu Kotler \& Keller (2016) menjelaskan media sosial sebagai sarana bagi para konsumen untuk bertukar dan berbagi informasi baik dalam benuk teks, gambar serta video, dengan perusahaan atau merek maupun sebaliknya. Dengan demikian kegiatan pemasaran media sosial menjadi sebuah bentuk dari pemasaran langsung maupun tidak langsung dan yang bertujuan untuk membangun kesadaran, mengenal, mengingatkan kembali, dan juga merupakan sebuah langkah langsung terhadap sebuah merek, bisnis, produk, jasa, orang atau hal lainnya namun dikemas menggunakan alat-alat di social web seperti social networking, content sharing, blogging, micro blogging, dan social bookmarking (Guenelius, 2011).

Kotler dan Keller (2016), menjabarkan periklanan yang baik dan efektif mengandung pesan ideal yang dapat menarik perhatian, menimbulkan rasa ingin tahu lebih lanjut, menimbulkan keinginan, dan merangsang tindakan nyata. Teori Customer Service, merupakan petugas atau karyawan yang sengaja dibentuk untuk melayani pelanggan atau nasabah oleh berbagai perusahaan seperti perbankan, asuransi, penggadaian, lembaga pembiayaan, leasing, transportasi, rumah sakit atau lainnya Khasmir (2017). Teori Pengambilan keputusan merupakan proses psikologis dasar yang memainkan peranan penting dalam memahami 
bagaimana konsumen secara aktual dalam mengambil keputusan pembelian (Kotler \& Keller, 2016), dengan langkah-langkah sebagai berikut: (1) Pengenalan masalah/kebutuhan; (2) Pencarian informasi; (3) Evaluasi alternatif; dan (4) keputusan pembelian perilaku pasca pembelian.

\section{Brand Awareness}

Pada sisi lain, brand awareness dapat berperan menandakan keberadaan, komitmen dan inti yang sangat penting bagi pemberi jasa. Bila kesadaran atas brand tinggi, maka kehadiran brand tersebut selalu dapat dirasakan, sebab sebuah brand dengan brand awareness tinggi biasanya disebabkan oleh beberapa faktor yaitu: (1) diiklankan secara luas, sehingga diketahui secara luas oleh masyarakat; (2) eksistensi yang sudah teruji oleh waktu, keberadaan merek yang telah berlangsung lama menunjukkan bahwa merek tersebut mampu memenuhi kebutuhan dan harapan konsumen; (3) jangkauan distribusi yang luas, sehingga memudahkan konsumen untuk mendapatkan produk tersebut; dan (4) merek tersebut dikelola dengan baik.

Brand dengan top of mind tinggi mempunyai nilai pertimbangan tinggi. Jika suatu merek tidak tersimpan dalam ingatan, merek tersebut tidak akan dipertimbangkan dalam keputusan pembelian. Biasanya merek yang disimpan dalam benak konsumen adalah merek-merek yang disukai atau dibenci (Durianto, 2004).

\section{METODE PENELITIAN}

Penelitian ini menggunakan metode survei yaitu merupakan pengumpulan data sampel, untuk mendapatkan informasi kuantitatif terkait opini publik, sikap, maupun fenomena sosial (Purwanto \& Sulistyawati, 2017). Penelitian ini menggunakan teknik accidental sampling. Menurut Sugiyono (2015), accidental sampling adalah teknik penentuan sampel berdasarkan kebetulan, yaitu siapa saja yang secara kebetulan bertemu dengan peneliti dapat digunakan sebagai sampel, bila dipandang orang yang kebetulan ditemui adalah sesuai sebagai sumber data. Pada penelitian ini Skala yang digunakan peneliti adalah skala Likert. Karakteristik responden yang peneliti tentukan di dalam kuesioner antara lain usia, jenis kelamin, tempat tinggal/domisili, tingkat pendidikan, pengeluaran dalam sebulan dan pekerjaan.

Untuk menentukan sampel, peneliti menggunakan rumus Slovin sebagai berikut:

$n=\frac{N}{1+N(e)^{2}}$

Di mana, $\mathrm{n}$ = Ukuran Sampel, $\mathrm{N}=$ Ukuran populasi, $\mathrm{e}=$ Persen kelonggaran ketidaktelitian karena kesalahan pengambilan sampel (sampling error) yang masih dapat ditoleransi atau diinginkan, peneliti memakai sampling error $10 \%$.

\section{HASIL DAN PEMBAHASAN}

Menurut sustainability report Luxebarbershop di tahun 2019, Jumlah pengunjung rata-rata dalam sebulan adalah 600-800 pengunjung. Besarnya sampel dalam penelitian ini adalah sebagai berikut: 


$$
\begin{aligned}
n & =\frac{600}{1+(600 \times(0.1))^{2}} \\
& =86 \text { responden }
\end{aligned}
$$

Pre-Test dilakukan untuk menghindari adanya kegagalan total, baik menggunakan uji validasi dan uji reliabilitas.

Pada penelitian ini, variabel X Instagram ads terdiri dari empat dimensi dengan tabel 14 pernyataan, variabel $\mathrm{X}$ terdiri dari dari: Dimensi Context, Communication, Collaboration, dan Connection. Sementara Variabel Y brand awareness terdiri dari dimensi dengan tabel 4 pernyataan, variabel Y terdiri dari: Dimensi Unaware of Brand, Brand Recognition, Brand recall, dan Top of Mind.

Uji Validitas adalah dasar pertimbangan untuk menentukan valid atau tidaknya pernyataan adalah dengan membandingkan $r$ hitung dengan $r$ tabel, bila $r$ hitung lebih besar daripada $r$ tabel, maka instrumen itu dinyatakan valid (Sugiyono, 2015). Dan hasil dari uji validitas Variabel X yang mempunyai 14 pernyataan dan variabel Y yang mempunyai 4 pernyataan adalah semua Valid.

Teknik atau rumus pengukuran reliabilitas yang digunakan dalam penelitian ini adalah Cronbach's Alpha. Menurut Siregar (2014), hasil uji reliabilitas dikatakan konsisten atau reliabel dengan menggunakan teknik ini, apabila nilai Cronbach's Alpha lebih besar dari o,6. Dan hasil uji reliabilitas variabel $\mathrm{X}$ dengan 14 pernyataan adalah 0,964 dan variabel $\mathrm{Y}$ dengan 4 pernyataan adalah 0,899 . Maka dapat disimpulkan bahwa seluruh instrumen pernyataan variabel $\mathrm{X}$ dan $\mathrm{Y}$ pada penelitian ini adalah reliabel, telah memenuhi syarat dan dapat mengukur apa yang diteliti.

Menurut Ghozali (2013), analisis korelasi memiliki sebuah tujuan untuk mengukur kekuatan asosiasi (hubungan) linear antara dua variabel atau lebih. Dari hasil penelitian ini maka dapat dijelaskan hasil analisisnya adalah adanya korelasi antara variabel X (Instagram ads) dengan variabel Y (brand awareness), di mana nilai koefisien korelasi (r) yang didapatkan sebesar o,914 (hubungan sangat kuat) dan arah yang positif.

Tabel 1. Hasil Uji Koefisien Determinasi

\begin{tabular}{lrrrr}
\hline \multicolumn{5}{c}{ Model Summary } \\
\hline Model & $\mathrm{R}$ & R Square & Adjusted R Square & Std. Error of the Estimate \\
\hline 1 & $.914^{\mathrm{a}}$ & 0.835 & 0.833 & 0.955 \\
\hline \multicolumn{4}{c}{ a. Predictors: (Constant), } \\
\multicolumn{4}{c}{ X_total } \\
Sumber: Data Olahan Peneliti (2020)
\end{tabular}

Hasil uji koefisien determinasi pada penelitian ini dapat diketahui bahwa nilai R sama besar dengan nilai Pearson Correlation pada uji korelasi sebelumnya yaitu sebesar 0,914. Nilai tersebut dapat diinterpretasikan bahwa hubungan antara variabel X (Instagram Ads) dan variabel Y (brand awareness) ada pada kategori sangat kuat. Hasil penelitian ini juga mendapatkan koefisien determinasi (KD) sebesar o,835. Dengan ini dapat diinterpretasikan bahwa besar kontribusi variabel X (Instagram ads) terhadap variabel Y (brand awareness) 
adalah sebesar 83,35\%, Sedangkan sisanya sebesar 16,65\% (100\%-83,35\%) dipengaruhi oleh faktor lain yang tidak diteliti dalam penelitian ini.

Mengacu pada teori yang dikemukakan oleh Perloff (2010), bahwa proses sikap dan kognitif seseorang dalam menganalisis isi pesan mengacu pada dua rute persuasi, yaitu sentral dan periferal. Dari hasil jawaban responden, dapat dilihat bahwa sebagian besar responden menyatakan 'setuju' dengan seluruh pernyataan yang ada dalam dimensi-dimensi Instagram ads (variabel X). Selain itu, seperti yang dikemukakan oleh Surachman (2008) bahwa terdapat empat tahap dalam proses brand awareness yang merupakan empat dimensi yang dipakai oleh peneliti untuk variabel Y (brand awareness), yang di antaranya adalah tidak mengenal suatu brand (unware of a brand), pengenalan brand (brand recognition), pengingat brand (brand recall), dan menjadi brand pertama yang teringat ketika nama brand disebutkan (top of mind). Dari hasil jawaban responden, dapat dilihat bahwa sebagian besar responden menyatakan 'setuju' dengan seluruh pernyataan yang ada dalam dimensi-dimensi brand awareness (variabel Y).

Berdasarkan hasil penelitian, maka peneliti dapat menarik kesimpulan sebagai berikut Terdapat pengaruh antara Instagram ads terhadap peningkatan brand awareness Luxebarbershop, Sarinah, Jakarta karena berdasarkan perhitungan dalam program SPSS versi 24, dapat diketahui bahwa nilai sig (o,00oo) lebih kecil $(<)$ daripada nilai taraf signifikan $(0,05)$. Dengan demikian dapat dinyatakan bahwa hipotesis Ho ditolak dan Ha diterima.

\section{SIMPULAN}

Kesimpulan umum dari nilai kontribusi variabel X (Instagram ads) terhadap variabel $\mathrm{Y}$ (brand awareness) adalah sebesar 83,5\%, sisanya sebesar 16,5\% dipengaruhi oleh faktor lain yang tidak diteliti atau diamati dalam penelitian ini, dan Instagram ads mempunyai korelasi sangat kuat terhadap meningkatnya brand awareness.

Beberapa saran akademis yang dapat diberikan, yaitu: apabila melakukan penelitian dengan tema yang sama, peneliti menyarankan untuk penelitian mendatang diharapkan dapat meneliti barbershop yang berbeda dan melihat topik permasalahan penelitian dengan sudut pandang yang berbeda, diadakan penelitian yang lebih mendalam, seperti meneliti mengenai testimoni dari orang-orang yang terpengaruh untuk datang mencoba layanan di barbershop tersebut, penelitian selanjutnya dapat melihat pengaruh media sosial barbershop terhadap brand image, brand loyalty, atau brand associations.

Selain itu pihak Luxebarbershop agar meneruskan menggunakan Instagram ads, karena terbukti berpengaruh dominan untuk meningkatkan brand awareness, dan admin Luxebarbershop diharapkan untuk dapat lebih kreatif membuat konten, serta pihak Luxebarbershop diharapkan membuat standar operasional kerja yang lebih baik lagi. 


\section{DAFTAR PUSTAKA}

Durianto, D. (2004). Strategi Menaklukkan Pasar Melalui Riset Ekuitas dan Perilaku Merek. Gramedia Pustaka Utama

Ghozali, I. (2013). Aplikasi Analisis Multivariate dengan Program IBM SPSS 21. Badan Penerbit Universitas Diponegoro.

Lafferty, B. A., Goldsmith, R. E., \& Newell, S. J. (2002). The Dual Credibility Model : The Influencer of Corporate and Endorser Credibility on Attitudes and Purchase Intentions. Journal of Marketing Theory and Practice, 10(3), 1-11. https://doi.org/10.1080/10696679.2002.11501916

Khasmir. (2017). Customer Service Excellent: Teori dan Praktik. Raja Grafindo.

Kotler, P., \& Keller, K. L (2016). Marketing Management (15th ed.). Pearson Education, Inc.

Nummila, M. (2015). Successful Social Media Marketing on Instagram Case: @minoshoes (No. Publikasi 17669) [Skripsi Sarjana Strata 1, Haaga-Helia University of Applied Sciences]. Theseus.

Patrick, D. P., Bergh, J. V. D., \& Geuens, M. (2017). Marketing Communications: A European Perspective. Pearson Education.

Paquette, H. (2013). Social Media as a Marketing Tool: A Literature Review (No. Publikasi 1001) [Makalah Kajian Literatur Magister, University of Rhode Island]. DigitalCommons@URI.

Perloff. R. M. (2010). The Dynamics of Persuassion Communication and Attidues in the 21st Century (4th ed.). Lawrence Eribaum Associates.

Prisgunanto, I. (2014). Komunikasi Pemasaran Era Digital. Prisani Cendekia.

Purwanto, E. A. \& Sulistyawati, D. R. (2017). Metode penelitian kuantitatif. Gaya Media.

Rouse, M. (2011, Maret 24). Definition: Social Media Marketing (SMM). TechTarget. https://whatis.techtarget.com/definition/social-media-marketing-SMM

Sagiyanto, A. \& Sulfiah, A. (2020). Pemanfaatan Instagram Sebagai Media Promosi Produk Haus Melalui Akun @Haus.Indonesia.Jurnal AKRAB JUARA, 5(2), 97-114.

Siregar, S. (2014). Metode penelitian kuantitatif. Dilengkapi dengan Perbandingan Perhitungan Manual \& SPSS. Kencana.

Stanton, W. J. (2003). Manajemen Pemasaran: Analisis, Perencanaan, Pelaksanaan dan pengendalian (Y. Lamarto, Trans.). Erlangga.

Sugiyono. (2015). Metode Penelitian Kuantitatif, kualitatif dan R\&D. Alfabeta. 
Surachman, S. A. (2008). Dasar-Dasar Manajemen Merek Alat untuk Memenangkan Persaingan. Bayumedia Publishing.

Tarsakoo, P. \& Charoensukmongkol, P. (2020). Dimension of social media marketing capabilities and their contribution to business performance of firms in Thailand, Journal of Asia Business Studies, 14(4), 441-461. https://doi.org/10.1108/JABS-072018-0204 